\title{
O sofrimento ético no mundo do trabalho dos jornalistas
}

Thales Vilela Lelo

Universidade de São Paulo, São Paulo, Brasil

\section{Resumo}

Com base em uma análise qualitativa de entrevistas semiestruturadas realizadas com 15 repórteres que atuavam no Estado de São Paulo em 2016, este artigo conceitua um fenômeno recorrente nas trajetórias de jornalistas brasileiros e escassamente documentado pela literatura, a saber, o sofrimento ético. Tencionando duas chaves explicativas oferecidas pela sociologia do jornalismo que tomam relatos de infração aos códigos deontológicos como sintoma da inconsciência de classe entre os comunicadores ou como resultado das transformações nas organizações de mídia, este estudo recupera o arcabouço da economia política da comunicação para demonstrar a persistência histórica do sofrimento ético.

\section{Palavras-chave:}

Jornalismo. Ética. Trabalho. Sofrimento. Entrevista.

\section{Introdução}

Inicio o artigo com a apresentação de três relatos que, como argumentarei nas páginas subsequentes, são emblemáticos de um tipo de sofrimento característico ao exercício profissional do jornalismo no Brasil. Quando atuou na editoria de arte de um portal de notícias de abrangência nacional, David ${ }^{1}$, que à época era responsável pela produção multimídia do site, afirma ter sido orientado pela direção do veículo a elaborar infográficos com dados distorcidos de pesquisas sobre a educação no Estado de São Paulo, visando a promover figuras políticas da região que tinham a simpatia da organização. O jornalista Vinicius vivenciou experiência similar em 2016, período em que atuava na cobertura em tempo real de economia e política para uma agência de notícias. Por instrução editorial da diretoria da empresa, foi delegada à sua equipe a tarefa de produzir matérias que fabricassem a expectativa de que os índices econômicos do Brasil 
iriam melhorar com o impeachment da presidenta Dilma Rousseff. A apuração da pauta, entretanto, frustrou as orientações da chefia que, por fim, aconselhou a redação a enquadrar os dados de modo a retratar a realidade que almejavam que a agência apresentasse ao leitor. Já a repórter Tereza - que exerceu, por dois anos, a função de correspondente no interior de São Paulo para um portal de circulação nacional - alega que, diante das primeiras suspeitas de que o ex-presidente Lula teria participado de esquemas de corrupção, a empresa supervalorizou a pauta encaminhada a ela, constrangendo-a a compor uma reportagem baseada em informações de veículo concorrente, sugerindo que o ex-presidente de fato estaria envolvido em atos ilícitos, algo impossível de ser comprovado naquele momento.

Os relatos supracitados compõem um corpus de 15 entrevistas semiestruturadas realizadas por ocasião da investigação intitulada "Reestruturações produtivas no mundo do trabalho dos jornalistas: precariedade, tecnologia e manifestações da identidade profissional". Os diálogos ocorreram via Skype entre 11 de abril e 12 de setembro de $2016 \mathrm{com}$ jovens jornalistas (entre 24 e 34 anos quando do contato) com experiência em plataformas digitais de abrangência nacional, todas elas sediadas no Estado de São Paulo. As conversas foram gravadas para posterior transcrição e análise qualitativa. O roteiro foi composto de cinco subgrupos de indagações (formação; trajetória profissional; condições de trabalho; condições de saúde; percepções gerais sobre a área) enfocadas em compreender a inserção dos interlocutores em um mercado em profunda reestruturação (FÍGARO, 2013; LIMA; GROHMANN, 2013; MICK; LIMA, 2013; PEREIRA; ADGHIRNI, 2011).

Dentre as questões formuladas, aquela que estimulou relatos como os de David, Vinicius e Tereza, indagava à fonte se em algum momento ao longo de sua carreira ela já havia sido orientada a produzir matérias que violassem o Código de Ética dos Jornalistas Brasileiros. Saltaram aos olhos que, dos 15 colaboradores, somente cinco responderam negativamente à pergunta. O dado é preocupante se levarmos em consideração que os comunicadores que participaram da pesquisa tinham entre um ano e meio e 11 anos de experiência no mercado quando ocorreram as entrevistas. Além disso, nenhum deles vivenciou um contexto de repressão e censura à imprensa, típicos do período ditatorial (ABREU, 2002; FONSECA, 2002). Dentre as práticas citadas, as fontes mencionaram terem sido coagidas a distorcer dados com o intuito de promover figuras políticas aliadas dos veículos (prejudicando outras que não eram próximas da organização); omitir informações que poderiam afetar atores políticos 
associados aos diretores da empresa; ou ainda receber pautas "encomendadas" por agentes públicos ou anunciantes.

Nas seções seguintes deste artigo pretendo argumentar que o sofrimento ético é uma experiência de assédio moral ${ }^{2}$ persistente na história do jornalismo brasileiro, muito embora tenha recebido atenção insuficiente da literatura especializada. Analisando os relatos dos entrevistados, em primeiro lugar serão tensionadas duas chaves explicativas provenientes da sociologia do jornalismo que oferecem interpretações macroestruturais dos dados coletados: a primeira delas compreenderia os desvios éticos como indicadores de uma profunda inconsciência de classe entre os comunicadores, enquanto que a segunda consideraria tais ocorrências como consequência das recentes transformações no mundo do trabalho desses profissionais. As limitações heurísticas destas duas linhas argumentativas serão devidamente apontadas recorrendo ao arcabouço da economia política da comunicação. Na sequência, ofereço uma conceituação do sofrimento ético a partir de uma perspectiva clínica do trabalho, propondo que tal noção permite compreender não só os efeitos deste tipo de assédio nas trajetórias e na saúde mental dos entrevistados, mas também as táticas empregadas por eles para preservarem sua dignidade profissional e os elos dessa manifestação de sofrimento com outras vivências negativas no espaço laboral (como a ausência de políticas de reconhecimento nas redações).

\section{Nem rendição subserviente, nem novidade histórica}

Ao discorrerem sobre situações que consideram infrações à ética conforme os códigos deontológicos do jornalismo, alguns dos interlocutores desta pesquisa rememoram casos em que foram tolhidos de reportar acontecimentos de relevância política e social por eles afetarem negativamente figuras públicas "aliadas" das empresas em que trabalhavam ou por não estarem em consonância à linha ideológica do veículo. É o caso de Aline, com experiência em redações digitais que realizam cobertura nacional. Em 2010, durante as eleições para governador no Estado de São Paulo, a comunicadora relata que muitos assuntos de interesse do leitor eram simplesmente censurados porque poderiam prejudicar a campanha de determinados candidatos. Em suas 
palavras, "você percebia que tinham políticos que eram, digamos, parceiros da empresa, aliados da empresa, e outros não. Os que eram inimigos da empresa não se falava, não se reportava, não se fazia matéria" (DEPOIMENTo extraído de entrevista concedida ao pesquisador em 14 de maio de 2016). A jornalista Tereza também se sentiu censurada pela direção do webjornal em que atuava quando, na ocasião da crise hídrica que abalou o Estado de São Paulo entre 2014 e 2016, teve propostas de pauta recusadas por afetarem negativamente a gestão do então governador Geraldo Alckmin.

Outra manifestação deste incentivo à infração da ética jornalística vem à tona nas falas de repórteres que denunciam terem recebido pautas por solicitação de empresários próximos dos diretores dos veículos que os contrataram. Antônio, à época editor da homepage de um dos principais portais de notícia do país, menciona que já suspeitou das motivações de uma série de propostas que chegaram à sua mesa, como quando a sua equipe desenvolveu uma reportagem sobre o turismo em Santos porque o diretor de redação tinha relação pessoal com um comerciante da cidade. O comunicador Ramon, com passagem em várias organizações jornalísticas de São Paulo, também já foi vítima de coação moral para produzir conteúdos que afrontavam a sua ética profissional, em especial sendo incitado a escrever textos sobre temas anódinos (também chamados de "cascatas" no jargão jornalístico) a pedido de sua chefia imediata ou da própria gerência da empresa. Comentando sobre as diversas circunstâncias ao longo de sua carreira em que se sentiu persuadida a violar a ética jornalística, a repórter Nathália identifica que muitos processos de demissão que sofreu foram provavelmente motivados por sua indisposição em transgredir tais princípios:

\begin{abstract}
Já me pediram pra pegar, por exemplo, pesquisas, e recortar parte daquele estudo de uma maneira que fosse beneficiar o cliente, mas o estudo completo não era naquele sentido. Então, não. Manipular a informação, é isso. Já me pediram isso e eu não fiz. Em alguns lugares foi compreendido, em outros lugares não, né? E eu acho que isso desencadeou alguns processos de demissão na minha trajetória, embora eles não tenham assumido (DEPOIMENTO extraído de entrevista concedida ao pesquisador em 25 de agosto de 2016).
\end{abstract}

Há uma forte inclinação em identificar nos discursos desses trabalhadores uma afinação acrítica à cultura corporativa do patronato - que prioriza os interesses financeiros das empresas de comunicação em face dos fundamentos éticos do jornalismo. Este prisma interpretativo, seja alicerçado na perspectiva teórica de Bourdieu (1996) ou ainda na abordagem marxista de Genro Filho (2012), possui ampla penetração em expoentes da sociologia 
do jornalismo nacional, a exemplo das reflexões de Abreu (1998), Moretzsohn (2002) e Fonseca (2002). Tal visada nos levaria a concluir que a adesão frequentemente acrítica dos jornalistas às imposições para transgredir as prerrogativas morais do campo seria consequência de uma ausência de consciência de classe na categoria.

É incontestável que predomina entre os entrevistados um descrédito nas associações de trabalhadores (quando indagados se o Sindicato dos Jornalistas Profissionais no Estado de São Paulo (SJSP) era representativo para a categoria, todos os 15 interlocutores responderam negativamente), bem como uma reincidência de deslocamentos profissionais em decorrência de sucessivas demissões e de formas precárias de contratação (programas de trainees, freelancers, pessoa jurídica (PJ), microempreendedor individual (MEI) etc.). Todavia, seria forçoso e cruel inferir que os entrevistados aderem acriticamente às imposições para transgredirem os fundamentos morais do campo por compactuarem com o universo de valores do patronato. Se assim o fosse, não seria nem mesmo possível a eles tematizarem as experiências supramencionadas como violações aos seus compromissos com a profissão. Outrossim, sustentar essa leitura também restringe as fontes de sofrimento 3 no trabalho dos comunicadores aos aspectos mais documentados de suas rotinas pela literatura, a exemplo do assédio moral e sexual que desponta em suas relações com colegas, superiores e fontes (BULHÕES; RENAULT, 2016; HELOANI, 2005; REIMBERG, 2015).

Outra chave interpretativa destes depoimentos oferecida pelo arcabouço da sociologia do jornalismo nos remete ao diagnóstico de um deslocamento na identidade profissional do comunicador a partir das reestruturações produtivas que vêm promovendo transformações nas redações - prejudicando a necessária independência jornalística em face dos imperativos financeiros das empresas. Caminham por esta direção as discussões sobre o crescente déficit de responsabilização dos repórteres por seu ofício (ADGHIRNI, 2012; FÍGARO, 2013; PEREIRA; ADGHIRNI, 2011) e sobre a acentuada autocensura daqueles que exercem suas atividades via regimes frágeis de contratação (FÍGARO; LIMA, 2016). Em síntese, as pressões derivadas da intensificação dos tempos de produção da notícia, da convergência 
multimídia e do enxugamento dos quadros profissionais (FÍGARO, 2013; FONSECA, 2006; MORETZSOHN, 2014) fomentariam um terreno fértil para a violação da ética jornalística.

Muito embora seja possível sustentar a tese de que as recentes transformações no mundo do trabalho dos jornalistas produzem impactos notáveis na formação da identidade profissional (criando terreno propício para que muitos trabalhadores se entendam como "técnicos" em processamento de informação [ADGHIRNI, 2012] dispostos a abdicarem de sua autonomia em prol do emprego), não é possível desconsiderar que os impedimentos ao exercício ético da profissão conforme os códigos deontológicos da área não advêm somente destas recentes mutações na identidade profissional. Como um histórico de pesquisas em economia política da comunicação já evidencia há décadas (ALBUQUERQUE; PINTO, 2014; ABREU, 2002; BOLAÑO, 2007; FONSECA, 2003; PAGANOTTI, 2017; REBOUÇAS, 2006), a forte concentração de mídia no Brasil por um número reduzido de grupos familiares e políticos é uma barreira à independência jornalística que antecede à implementação de novas tecnologias nas redações ou o enxugamento dos postos de trabalho, haja vista que tal concentração se faz presente desde o início da colonização portuguesa, passando pela chegada da imprensa no país com a corte no século XIX e se estendendo ao longo de todo o $\mathrm{xx}$ (do Estado Novo às décadas que sucederam ao período de redemocratização).

Conforme relatório publicado pelo coletivo Intervozes em parceria com a organização Repórter sem Fronteiras ${ }^{4}$, atualmente cinco grupos de mídia controlam mais da metade dos veículos do país, consequência direta do “coronelismo eletrônico" (distribuição e renovação de concessões de rádio e televisão para parlamentares ou aliados políticos), da baixa fiscalização na renovação das concessões, do financiamento estatal de empresas privadas de comunicação via anúncios, do controle de emissoras por Igrejas, da dependência dos anunciantes como meio de manter as receitas da publicação, e da escassez de incentivos para o desenvolvimento de canais independentes, comunitários e alternativos.

Os oligopólios de mídia nacionais infringem sistematicamente o texto da Constituição Federal de 1988 que prevê, em seu capítulo V, artigo 220, parágrafo 5 , que “ os meios de comunicação não podem, direta ou 
indiretamente, ser objeto de monopólio ou oligopólio" (BRASIL, 1988) e são, portanto, marca da ausência de dispositivos de regulamentação dos meios ao longo de toda a história do país ${ }^{6}$. Em outras palavras, o fenômeno identificado aqui é anterior às recentes reestruturações no mundo do trabalho dos jornalistas que, evidentemente, tem tornando ainda mais inexequível o exercício do ofício conforme os códigos deontológicos devido à formação de "exércitos de reserva" de comunicadores vitimados por demissões coletivas e que possuem parcas proteções legais para resistirem ao aparelhamento jurídico dos grupos de mídia hegemônicos.

Outrossim, a modernização autoritária da imprensa no país ${ }^{7}$, ocorrida dos anos de 1950 em diante (AlBUQUeRQUe, 2010; ABREU, 2002; FONSECA, 2003) sob incentivo financeiro do regime militar (que encampava um projeto de segurança e unificação nacional via expansão dos meios de comunicação) conduziu à transformação da mentalidade dos principais grupos jornalísticos, que assumiram ostensivamente sua feição empresarial. Tal período também foi caracterizado pela extinção de veículos de imprensa com linhas editoriais divergentes ao regime militar e pela concentração de recursos e tecnologia nas mãos de empresários que eram financiados em troca da submissão ao governo. Destarte, se muitos jornalistas de prestígio apoiaram o golpe militar de 1964, com o correr dos anos e com o aumento das repressões muitos passaram a se opor ao regime, mas o medo de retaliação foi reduzindo o seu compromisso político e os confinando em editorias que lhes minimizariam os riscos de cerceamento (ABREU, 2002).

O AI-5 (1968-1978) impôs censura prévia aos meios de comunicação e levou à prisão, à tortura e ao assassinato diversos repórteres que não se submetiam ao governo. Não obstante, jornalistas à época ligados ao Partido Comunista Brasileiro (PCB) atuaram na grande imprensa se conformando ao regime por meio da autocensura e da discrição,

5 Além disto, o texto da Constituição ainda prevê a complementaridade nas políticas de comunicação brasileiras, distribuídas entre organizações públicas, privadas e estatais.

6 Cabe pontuar que a quase inexistência de influência do Estado e da sociedade civil na elaboração das políticas de comunicação nacionais torna impraticável a obediência ao texto legal.

7 Na perspectiva de Albuquerque (2010), as narrativas míticas sobre a modernização da imprensa no Brasil assumem como marcos de referência as reformas autoritárias do Diário Carioca na década de 1950; e da Folha de S. Paulo, em 1980, reformas estas que encetaram um discurso de profissionalização pautado pela imposição de dispositivos formais (como as fórmulas textuais adaptadas do jornalismo estadunidense e os manuais de redação) pelos chefes e editores aos seus subordinados à custa da autonomia destes em compartilharem efetivamente seus valores profissionais. 
evitando assim serem denunciados aos órgãos de repressão (ALBUQUERQUE; SILVA, 2007). O efeito desta conduta cautelosa persistiu mesmo após a revogação do AI-5 como aspecto do mundo do trabalho dos jornalistas no país, já não mais ligado ao receio da punição, mas sim como meio de evitar demissões ou processos judiciais (FÍGARO; LIMA, 2016).

Segundo Abreu (2002), com o fim da ditadura e o início do processo de redemocratização, as reformas editoriais da Folha de S. Paulo e a implementação de um novo Manual de Redação levaram a uma produção jornalística mais despolitizada (algo que, em 1985, motivou a demissão de mais de 50 profissionais que se recusaram a adotar o novo código normativo da publicação). Aos poucos, muitos repórteres que se viam como defensores do interesse público passaram a adotar uma visão pragmática de mercado. Neste mesmo período, muito embora já não vivêssemos em uma ditadura militar, os comunicadores continuaram entronizando o espírito de repressão do regime. A autocensura ainda era uma constante nas práticas dos repórteres, que evitavam denunciar escândalos políticos do governo de José Sarney por temerem retaliações (ABREU, 2002).

À vista deste breve panorama histórico, é fato que ainda hoje uma parcela expressiva dos jornalistas brasileiros (a exemplo dos 15 interlocutores desta pesquisa), atuam em veículos que permanecem dependentes de incentivo via publicidade estatal, concessões públicas e verbas de anunciantes. O investimento feito é devolvido, frequentemente, pelos índices de audiência, métricas de acesso e/ou acordos políticos indevidos. Neste cenário, as tentativas frustradas de criação de um Conselho Federal de Jornalistas (apto a julgar os desvios éticos da imprensa [DALMONTE, 2011]), a carência de discussão parlamentar em períodos de renovação de concessões de rádio e televisão (BOLAÑO, 2007), o boicote das empresas de mídia à $1^{a}$ Conferência Nacional de Comunicação (Confecom) em dezembro de 2009 (PAGANOTTI, 2017), além da minoritária representatividade da sociedade civil na composição do Conselho de Comunicação Social do Congresso Nacional (REBOUÇAS, 2006) se somam às campanhas difamatórias levadas a cabo pelos veículos da grande imprensa sempre que emerge qualquer ameaça à manutenção dos oligopólios existentes (com vistas à democratização da mídia). Projetos em favor da regulamentação e responsabilização dos meios são logo reprimidos na esfera pública pelos grupos hegemônicos como se equivalessem à censura, em nítida instrumentalização dos discursos em favor da liberdade de expressão e da imprensa, que passam a equivaler aos direitos dos proprietários em detrimento dos direitos do cidadão (LIMA, 2010). 


\section{Conceituando o sofrimento ético no jornalismo}

Mas mesmo em face das significativas reconfigurações na cultura jornalística brasileira nas últimas décadas, que levaram a uma visão mais mercadológica da profissão, a uma reduzida consciência de classe entre os repórteres e ao abafamento de esforços em prol da implementação de políticas de regulamentação que garantiriam o cumprimento dos princípios da radiodifusão determinados pela Constituição de 1988, não houve uma completa domesticação dos trabalhadores às diretrizes das grandes corporações. Estudos como o de Mick e Lima (2013) ainda apontam que uma parcela expressiva dos comunicadores se identifica com uma visão de mundo progressista (quase 50\% dos seus entrevistados em 2012) e a maioria é formada em cursos de jornalismo que abarcam, em suas diretrizes curriculares, disciplinas sobre a deontologia profissional e os valores éticos do campo ${ }^{8}$. Não à toa uma parcela expressiva dos entrevistados pelos autores se disse à época favorável à criação de órgãos de autorregulamentação no setor.

Muito embora o Código de Ética dos Jornalistas Brasileiros, em seu capítulo IV, artigo 13, disponha de uma "cláusula de consciência" que, como consta no documento, prevê que o profissional pode "se recusar a executar quaisquer tarefas em desacordo com os princípios deste Código de Ética ou que agridam as suas convicções" (FENAJ, 2008, p. 3), diante do contexto delineado no tópico precedente fica patente a ineficiência deste dispositivo como meio de garantir o exercício responsável da profissão em um mercado altamente oligopolizado. Sem aparatos adicionais de regulação do setor, o estímulo à violação dos princípios presentes no código deontológico é coerente com a exigência mercadológica de paulatina expansão dos lucros? .

Retomando o corpus de entrevistas semiestruturadas que motivaram este estudo,

8 É fundamental alertar que não se propõe aqui instaurar uma dicotomia entre Universidade e mercado, como se as Instituições de Ensino Superior representassem o polo da virtude intocado pela racionalidade instrumental das mídias corporativas. A recente discussão sobre os fundamentos históricos e culturais das Diretrizes Curriculares do Jornalismo levantada por Albuquerque e Silva (2015) é emblemática neste sentido por pontuar como exigências corporativas e tecnicistas do mercado invadiram paulatinamente os currículos dos bacharelados em Comunicação.

9 Segundo McManus (2009), se a probabilidade de um acontecimento ser retratado na mídia em um veículo socialmente responsável é diretamente proporcional ao seu impacto junto ao interesse público, em um modelo pautado por um viés estritamente mercadológico esta equação é distorcida e a probabilidade de que um acontecimento seja retratado passa a ser inversamente proporcional aos prejuízos que a informação possa causar em investidores e anunciantes da empresa e ao custo gerado pela cobertura; e diretamente proporcional às expectativas de apelo ao consumidor-alvo dos anunciantes que financiam o veículo. 
um elemento que sobressaiu em todos os depoimentos de comunicadores que assumiram terem sido constrangidos a adulterar dados visando beneficiar empresas ou atores políticos que possuíam alianças impróprias com os veículos que os empregaram, ou ainda que relataram terem sido tolhidos de realizar coberturas de notável relevância pública por restrições editoriais ou ordens de superiores, e mesmo entre aqueles que indicaram terem sido forçados a produzir matérias a partir de pautas "encomendadas" pela chefia, é que eles não somente evidenciaram uma dolorosa consciência do áspero contraste entre os fundamentos éticos do campo e as práticas organizacionais das empresas de mídia, bem como assinalaram o sofrimento resultante desta experiência de serem compelidos a infringirem sua dignidade no trabalho. Ademais, em parcela significativa dos relatos os jornalistas também apontavam as táticas que adotaram com o objetivo de contornar ordens que estivessem em frontal descompasso à ética jornalística, como examinaremos adiante.

Com base na literatura que discorre sobre a atuação dos comunicadores brasileiros no período da ditadura civil-militar, e levando em consideração a recorrência sistemática dessas experiências nefastas nas carreiras dos repórteres entrevistados por esta pesquisa (avaliando retrospectivamente suas trajetórias, os 10 interlocutores narraram mais de uma circunstância em que foram coagidos a cometer deliberadamente deslizes éticos), constato a persistência de um sofrimento ético no processo de inserção destes profissionais nas organizações jornalísticas - decorrente não só da percepção de contínua impossibilidade de exercício do ofício em consonância aos códigos deontológicos, mas também, como veremos a seguir, da ausência sistemática de políticas de reconhecimento na redação. Esta forma de violência simbólica presente nas empresas de mídia integra o elenco de patologias organizacionais à saúde dos jornalistas, constituído, como documentado em diversos estudos, por assédios morais, sexuais, violência física, ameaças, tentativas de extorsão etc. (FENAJ, 2017; HELOANI, 2005).

Na matriz francófona de estudos clínicos sobre o trabalho, a noção de sofrimento ético desponta, especificamente, na obra de Dejours (2007), dedicada a descortinar criticamente os princípios de gestão neoliberais que foram progressivamente incorporados pelas organizações modernas, sem perder de vista suas repercussões em âmbito subjetivo e coletivo. Inspirado em Hannah Arendt, Dejours apreende na toxidade das relações laborais contemporâneas a manifestação da banalidade do mal tal como exposta no relato da filósofa alemã quando 
da condenação de Adolf Eichmann, tenente-coronel do regime nazista (ARENDT, 1999). De acordo com o clínico francês, a banalização da injustiça social no ambiente organizacional se reproduz sob a mesma premissa de retraimento da consciência intersubjetiva que caracterizara o universo de valores da Alemanha sob o poder de Adolf Hitler. A propagação desta distorção comunicacional no ambiente de trabalho corrói qualquer fagulha de reciprocidade que poderia pavimentar as relações laborais, viabilizando a racionalização de condutas eticamente reprováveis norteadas exclusivamente por objetivos financeiros - desconsiderando, na esteira, os códigos éticos que regem um campo profissional, e favorecendo, como corolário, o iminente desequilíbrio psicológico dos trabalhadores.

Mas diante destes sistemas de gerenciamento (que também penetram as redações jornalísticas), os profissionais não abandonam irrefletidamente os princípios normativos que pautaram sua formação educacional e no métier $^{10}$ (no caso em tela, princípios estes agrupados no Código de Ética dos Jornalistas Brasileiros), e é por esta razão que o sofrimento que experimentam nestas situações é especialmente lancinante, pois exige de cada um a traição de ideais que estiveram presentes em diversas etapas de sua construção como os jornalistas que são hoje.

Ao conceituar a existência de um sofrimento peculiar que perpassa o discurso de repórteres constrangidos por superiores a desrespeitarem sua dignidade profissional, não se quer aqui desresponsabilizar tais trabalhadores pelos eventuais deslizes que possam ter cometido em prejuízo do interesse público, mas sim ponderar que não é sem angústia que eles acatam as ordens mais reprováveis de uma perspectiva ética. Sendo o trabalho vetor de um "debate de normas" (SCHWARTZ, 2011) e os Códigos de Ética, em certa medida, prescrições do trabalho normatizadas como referências de conduta em situações ideal-típicas (necessariamente reinventadas à luz das vicissitudes do real), o que ocorre nas circunstâncias em que emana o sofrimento ético é também a percepção de que a "potência de agir" (CLOT, 2007) do profissional foi dramaticamente tolhida.

Dito isto, cabe ressaltar, de saída, a visível discrepância entre os depoimentos das cinco entrevistadas que alegaram nunca terem sido coagidas a infringir os fundamentos éticos da profissão e os outros 10 
que reportaram ocorrências desta natureza em suas trajetórias. Dentre as cinco, nenhuma registrou ter necessitado de ajuda terapêutica ou médica para lidar com sua rotina de trabalho e também declararam, em linhas gerais, não terem se arrependido da escolha pelo jornalismo. Entre estas cinco interlocutoras também há uma sinergia no que diz respeito à percepção de terem sido reconhecidas pelos colegas e superiores nas empresas em que atuaram. Não obstante se possa aventar a possibilidade de que tal reconhecimento seja ideológico (HONNETH, 2006) - ou seja, uma condecoração simbólica pela subserviência ou docilidade em atender qualquer sorte de diretrizes vindas de editores, chefes de redação e diretores - ou ainda que o nexo entre reconhecimento e ausência de coação para cometer desvios éticos não é causal - visto que ser submetido a jornadas extenuantes e a vínculos contratuais precários também pode minar, substancialmente, as fontes de reconhecimento no trabalho não é razoável desconsiderar o fato de que a sujeição reiterada à infração de normas profissionais historicamente consolidadas e estimadas por toda uma categoria causa prejuízos sensíveis à saúde mental e física dos jornalistas.
David, que fora instruído mais de uma vez a distorcer infográficos para favorecer a imagem dos políticos parceiros de duas das empresas em que trabalhou, avalia que nesse período em muitas circunstâncias padecera de um desgaste moral por sentir que não estava mais entregando um conteúdo de qualidade ao leitor. Na mesma época, ele também ressalta ter buscado auxílio terapêutico para enfrentar crises de ansiedade e estresse que continuamente o forçavam a abandonar o ambiente da redação. O interlocutor contrasta uma experiência anterior em um veículo de abrangência nacional (em que tinha orgulho de seu trabalho pelo cuidado em atender aos fundamentos éticos e técnicos da profissão) e a sua atuação posterior como ilustrador web nessas organizações que o levaram ao ponto de saturação. Dispensado de suas funções em uma das recentes ondas de cortes coletivos que vem atingindo os principais veículos de imprensa ao menos desde $2012^{11}$, decidiu, por fim, abandonar a área: "Eu decidi que não ia mais trabalhar com jornalismo, porque eu fui em uma decrescente, né? Eu fui de um ambiente muito bom, muito estável, com pessoas muito cuidadosas, a ambientes completamente imbecis" (DEPOIMENTO extraído de entrevista concedida ao pesquisador em 11 de abril de 2016). 
À mesma conclusão chegou Ramon. Após alguns anos trabalhando em redações vitimadas por cortes coletivos, com carga descomunal de atividades, abusos de superiores e coações para infringir os códigos deontológicos (sendo impelido a escrever matérias sem ter o tempo adequado para apuração ou sobre temas desprovidos de qualquer interesse público) o repórter foi progressivamente se exaurindo com o mercado, até decidir que não mais atuaria no jornalismo. Esta resolução também é respaldada por uma sensação análoga de denegação de reconhecimento por parte dos setores administrativos das empresas em que trabalhou e da percepção de que sofrera um princípio de depressão quando esteve em um grande portal de notícias com matriz em São Paulo.

Outras duas fontes que participaram desta investigação e que também foram levadas a cometer deslizes éticos a pedido de superiores igualmente abandonaram o jornalismo. Em suas decisões, a desilusão com a carreira não decorrera unicamente dessas orientações que receberam para violar o Código de Ética dos Jornalistas Brasileiros - já que o deslocamento de área se trata sempre de um somatório de fatores (como péssimas condições de trabalho, baixa remuneração, vínculos trabalhistas frágeis etc.) - mas o sofrimento ético, indubitavelmente, é uma das motivações presentes nestes relatos. Para a repórter Alice, que já foi coagida a distorcer informações sobre a vida de celebridades quando trabalhou para um site de entretenimento e afirma nunca ter sido reconhecida nas redações em que atuou, em determinado momento a sobrecarga emocional era tamanha que ela não mais conseguia lidar com a profissão sem ajuda clínica constante. Dispensada de suas funções, ela ainda não sabe se algum dia voltará ao jornalismo. Já Priscila, que no transcorrer de oito anos foi repórter em alguns dos mais renomados portais de notícia brasileiros (e que em determinadas situações teve o enfoque de suas matérias adulterado por editores), a saída do jornalismo lhe permitiu usufruir de uma satisfação que ela considera impossível na grande imprensa.

Mas para os outros interlocutores que informaram terem sido vítimas de sofrimento ético em suas trajetórias, a persistência na carreira não equivale, evidentemente, a uma submissão completa aos desígnios moralmente questionáveis de superiores e a uma rendição aos ditames do mercado, mas sim, no mais das vezes, a um enfretamento astucioso com vistas a não descumprirem os princípios éticos que julgam fundamentais à prática jornalística. Por esta razão, estes entrevistados não somente enfatizaram os impactos deletérios do sofrimento ético em sua saúde, mas também se preocuparam em ressaltar as estratégias silenciosas que empregaram para não 
se tornarem integralmente cúmplices destas infrações à deontologia jornalística, conservando sua dignidade parcialmente incólume.

Um exemplo dessas táticas é mencionado por Ramon que, designado a produzir notícias sobre temas irrelevantes, evitava assinar os textos, deixando-os com a rubrica da redação. Também Tereza que, como destacado anteriormente, fora induzida a supervalorizar a associação do ex-presidente Lula a escândalos de corrupção em um momento em que as suspeitas eram somente inferências estabelecidas pela própria imprensa, pontua que na reportagem em questão teve a preocupação de deixar claro que ainda não havia qualquer prova de que o político estivesse engajado em atos ilícitos.

Mas nem sempre as táticas adotadas são eficazes para apaziguar o conflito gerado entre as exigências de natureza estritamente mercadológica e a obediência aos princípios deontológicos do jornalismo. Por vezes, o emprego de certas estratégias que visam atenuar o sofrimento ético gerado na redação conduz o repórter à demissão, como o caso supracitado da comunicadora Nathália ilustra. Ao não aceitar distorcer dados de pesquisas visando beneficiar a imagem de anunciantes e políticos parceiros das empresas, além de se recusar a falsificar aspas atribuindo indevidamente citações a entrevistados, a profissional acredita que principiou muitos dos processos de demissão que a vitimaram nos últimos anos. Outras duas interlocutoras (Aline e Tereza) declaram terem passado por situações análogas. O caso de Tereza talvez seja o mais emblemático neste sentido: quando, por indicação do Ministério Público, fez uma reportagem exclusiva sobre o trabalho escravo de imigrantes residentes no interior de São Paulo que prestavam serviços para grandes redes varejistas, foi solicitada pelo fiscal do Ministério a não publicar a matéria enquanto a operação não atingisse os empresários envolvidos no caso, pois isso poderia prejudicar os trabalhadores, que não receberiam nenhum tipo de ressarcimento se estes gestores desaparecessem antes de serem oficialmente notificados. A entrevistada conversou com seu editor sobre a questão e ele não concordou com a sugestão de adiar a veiculação da reportagem, criticando-a por suposta falta de profissionalismo. A matéria inicialmente não foi publicada, sendo posteriormente lançada no jornal com mínimo destaque. Em decorrência deste fato, a repórter foi demitida por este mesmo editor pouco tempo depois.

A resistência ao sofrimento ético também pode acontecer por meio de um pedido de demissão formalizado pelo próprio jornalista. Quando Vinícius atuou em uma afiliada de uma grande empresa de comunicação no interior de Minas Gerais, na apuração de uma 
pauta descobriu que os fatos não correspondiam às intenções do editor com a matéria. Informou-o do ocorrido, mas o superior lhe pediu que construísse a reportagem da forma como havia sido delimitado em pauta (e não como os fatos evidenciavam). Não deu prosseguimento à apuração e se demitiu da empresa na sequência.

Pela linha argumentativa percorrida até aqui, é evidente que nem sempre é possível ao repórter descumprir ordens reprováveis feitas por seus superiores, motivadas por razões alheias ao jornalismo. Demitir-se ou se valer de táticas para evitar ter que lidar com o sofrimento ético são recursos que nem sempre estão à mão de profissionais mentalmente abalados e fisicamente sobrecarregados pelas reestruturações produtivas que acometeram a grande imprensa nos últimos anos. Por esta razão, a excursão qualitativa aos relatos dos repórteres entrevistados para esta pesquisa evidencia a existência de um vínculo indissociável (embora não linear) entre a vivência do sofrimento ético, a ausência sistemática de reconhecimento na redação e os efeitos danosos à saúde do jornalista. São os ambientes de trabalho mais insalubres (em função do descumprimento de leis trabalhistas) que amiúde se orientam unicamente por preceitos comerciais e, portanto, aqueles que menos se preocupam com a satisfação de sua equipe e com a ética jornalística - afinal, produzir materiais áudio-verbo-visuais com um quadro enxuto e sob o ritmo do tempo real, típico das redações digitais, implica necessariamente em relativizar fundamentos caros aos códigos profissionais. Por conseguinte, são também nestes espaços que se proliferam mais agudamente os desequilíbrios à saúde de repórteres e editores que desejam atuar conforme os fundamentos deontológicos do campo, mas que sentem que tal conduta seria inconciliável com as diretrizes que norteiam as redações que os admitiram.

Nas entrevistas realizadas, dos 10 interlocutores que mencionaram terem sido coagidos a infringirem a ética jornalística, todos frisaram a inexistência de políticas de reconhecimento por parte da gerência das organizações, pontuando que, quando foram simbolicamente estimados pelas matérias que produziram, os elogios foram indiretos ou vieram de colegas ou das próprias fontes que entrevistaram; já sete destes profissionais mencionaram terem procurado auxílio médico e terapêutico para tratarem de doenças físicas e psicológicas que germinaram como resultado do sofrimento experimentado no trabalho. É o que transparece exemplarmente no relato de Márcia, jornalista com passagem em diversos veículos de circulação nacional que declara nunca ter sido reconhecida pelos superiores (que somente procuravam a equipe para tecer duras críticas) e já ter sido obrigada a escrever 
textos encomendados pelo diretor geral de uma das redações em que esteve:

Eu tinha um plano de saúde bom. E o meu grande medo era esse, porque eu estava tão doente, eu vivia no hospital [...] então eles falaram que meu sistema imune estava zerado praticamente, né, e que era estresse, tanto que eu fui num médico, e ele falou: "eu não vou te receitar nenhum remédio, eu vou te receitar que você se demita". Eu nunca vou esquecer isso que ele falou: "o seu remédio hoje é a demissão" (DEPOIMENTO extraído de entrevista concedida ao pesquisador em 13 de abril de 2016).

Em sua narrativa, Márcia ecoa frustrações com a carreira que se manifestam nas falas de diversas outras fontes que participaram desta pesquisa e que também vivenciaram dolorosamente a ausência sistemática de reconhecimento no trabalho e o sofrimento de natureza ética. Em sua percepção, não obstante as sucessivas mudanças de emprego, as frustrações persistiam: "Minha insatisfação não era mais com o lugar A ou B, minha insatisfação era com a profissão [...] É um ambiente tão insalubre, tão horrível, as pessoas são tão loucas, ficam tão doentes" (DEPOIMENTO extraído de entrevista concedida ao pesquisador em 13 de abril de 2016).

\section{Considerações finais}

Informado por um conjunto de entrevistas semiestruturadas com jornalistas com passagem em alguns dos principais veículos de comunicação nacionais com base no Estado de São Paulo, este artigo partiu de um dado convergente nos relatos das fontes: a percepção de que suas trajetórias foram pontuadas por ocasiões em que foram impelidas a cometerem deliberadamente desvios éticos aos códigos deontológicos do campo. Este elemento comum nos depoimentos, que nos remete às condições estruturais de inserção na profissão, motivou um esforço analítico visando problematizar inferências teóricas consagradas pela sociologia do jornalismo nacional, que tomariam os depoimentos analisados seja como indício de inconsciência de classe entre os comunicadores, seja como consequência das recentes reestruturações nas empresas de mídia e da implementação de novas tecnologias de informação e comunicação nas redações.

Acentuando a persistência histórica de lógicas estritamente econômicas na grande imprensa brasileira (além de alianças controversas com o poder político), este estudo procurou, em primeiro plano, enriquecer a abordagem crítica sobre os obstáculos ao exercício ético do jornalismo em um panorama de reconfigurações nos mercados de mídia a partir do arcabouço da economia política da comunicação, posto que a concentração de propriedade dos meios e a escassez de conselhos de regulamentação 
são dados históricos que precedem às recentes transformações no mundo do trabalho dos comunicadores.

Ademais, discorrer sobre o sofrimento ético como um componente indissociável ao processo de integração dos comunicadores às redações permite compreender não só a saliente contradição entre uma identidade ocupacional forjada também por imperativos morais e um conjunto de práticas em frontal desacordo com eles, bem como seus impactos à saúde daqueles que vivenciam tal contradição - sujeitos estes amargamente conscientes dos deslizes que foram orientados a cometer.

Por fim, cumpre reforçar que a ênfase dada a esta manifestação de sofrimento no mundo do trabalho dos jornalistas não tem o propósito de minorar a importância das outras fontes de desestímulo à profissão ou ainda propor que esta fonte de deterioração da saúde mental e dos laços coletivos nas redações é a mais grave experiência de desrespeito que afeta os comunicadores brasileiros, mas tão somente ressaltar que este fenômeno, indevidamente negligenciado pela literatura especializada (incluindo estudos dedicados a analisar a saúde mental de jornalistas [HELOANI, 2005; REIMBERG, 2015; LIMA, 2018]), vem engendrando, ao longo da história, efeitos danosos nas carreiras dos trabalhadores.

\section{Referências}

ABREU, Alzira. Jornalistas: de românticos a profissionais. Antropolítica, n. 5, p. 7-19, 1998.

A modernização da imprensa (1970-

2000). Rio de Janeiro: Jorge Zahar, 2002.

ADGHIRINI, Zélia. Mudanças estruturais no jornalismo: travessia de uma zona de turbulência. In: PEREIRA, F.; MOURA, D.; ADGHIRNI, Z. (Org.) Jornalismo e sociedade: teorias e metodologias. Florianópolis: Editora Insular, 2012. p. 61-79.

ALBUQUERQUE, Afonso; SILVA, Marco. Preparados, leais e disciplinados: os jornalistas comunistas e a adaptação do modelo de jornalismo americano no Brasil. E-Compós, v. 9, p. 1-30, 2007.

ALBUQUERQUE, Afonso. A modernização autoritária do jornalismo brasileiro. Alceu, v. 10, n. 20, p. 100-115, 2010.

ALBUQUERQUE, Afonso; PINTO, Pâmela. O inferno são os outros: mídia, clientelismo e corrupção. FAMECOS, v. 21, n. 2, p. 541562, 2014.

ALBUQUERQUE, Afonso; SILVA, Marco. As Diretrizes Curriculares de Jornalismo e o modelo cartorial de ensino universitário.

Questões Transversais, v. 3, n. 5, p. 27-35, 2015. ARENDT, Hannah. Eichmann em Jerusalém: uma reportagem sobre a banalidade do mal. São Paulo: Companhia das Letras, 1999.

BOLAÑO, César. Qual a lógica das políticas de comunicação no Brasil? São Paulo: Paulus, 2007.

BOURDIEU, Pierre. Sobre a televisão. Rio de Janeiro: Jorge Zahar, 1996. 
BRASIL. Constituição da República Federativa do Brasil. Brasília: Senado Federal, 1988. Disponível em: $<$ https://www.presidencia.gov. $\mathrm{br} /$ casacivil/site/static/le.htm>. Acesso em: 26 jul. 2018.

BULHÕES, Juliana; RENAULT, David. A precarização da prática jornalística: uma revisão bibliográfica sobre o impacto das condições de trabalho na saúde e qualidade de vida do jornalista. Parágrafo, v. 4, n. 2, p. 166 174, 2016.

CLOT, Yves. A função psicológica do trabalho. Petrópolis: Vozes, 2007.

DALMONTE, Edson. É preciso ordenar a comunicação? Questionamentos acerca da necessidade de instâncias mediadoras entre mídia e público. Estudos em Jornalismo e Mídia, v. 8 n. 1, p. 21-38, 2011.

DEJOURS, Christophe. A banalização da injustiça social. Rio de Janeiro: Editora FGV, 2007.

A sublimação, entre sofrimento e prazer no trabalho. Revista Portuguesa de Psicanálise, v. 2, n. 33, p. 9-28, 2013.

FENAJ. Código de Ética dos Jornalistas Brasileiros. Brasília: Federação Nacional dos Jornalistas, 2008.

\section{Violência contra jornalistas e}

liberdade de imprensa. Brasília: Federação Nacional dos Jornalistas, 2017.

FÍGARO, Roseli. Atividade de comunicação e trabalho dos jornalistas. E-Compós, v. 16, n. 1, p. 1-20, 2013.

; LIMA, Cláudia; GROHMANN, Rafael.

As mudanças no mundo do trabalho do jornalista. São Paulo: Salta/Atlas, 2013.
; LIMA, Cláudia. A autocensura como aspecto da prática no mundo do trabalho dos jornalistas. Líbero, v. 19, n. 37, p. 71-80, 2016. FONSECA, Virgínia. A subordinação do jornalismo à lógica capitalista da indústria cultural. FAMECOS, n. 17, p. 126-141, 2002. Indústrias culturais e capitalismo no Brasil. Em Questão, v. 9, n. 2, p. 309-326, 2003. O declínio da notícia no jornalismo pós-fordista dos conglomerados multimídia. E-Compós, v. 2, p. 1-26, 2006.

GENRO FILHO, Adelmo. O segredo da pirâmide: para uma teoria marxista do jornalismo. Porto Alegre: Tchê!, 1987.

HELOANI, José. Mudanças no mundo do trabalho e impactos na qualidade de vida do jornalista. São Paulo: FGV, 2005.

HIRIGOYEN, Marie-France. Assédio moral: a violência perversa no cotidiano. Rio de Janeiro: Bertrand Brasil, 2002.

HONNETH, Axel. El reconocimiento como ideología. Isegoría, n. 35, p. 129-150, 2006.

LIMA, Samuel. Os impactos do mercado jornalístico na vida dos trabalhadores: um estudo sobre indicadores de saúde dos jornalistas brasileiros. In: ENCONTRO NACIONAL DE PESQUISADORES EM JORNALISMO, 16., 2018, São Paulo.

Anais... São Paulo: Associação Brasileira de Pesquisadores em Jornalismo, 2018. p. 1-16.

\section{LIMA, Venício. Liberdade de expressão $\mathrm{x}$}

liberdade de imprensa: direito à comunicação e democracia. São Paulo: Publisher Brasil, 2010.

McMANUS, John. The Commercialization of News. In: WAHL-JORGENSEN, K.; 
HANITZSCH, T. (Org.). The Handbook of Journalism Studies. New York and London: Routledge, 2009. p. 218-233.

MICK, Jacques; LIMA, Samuel. Perfil do jornalista brasileiro: características demográficas, políticas e do trabalho jornalístico em 2012. Florianópolis: Insular, 2013.

MORETZSOHN, Sylvia. Jornalismo em tempo real: o fetiche da velocidade. Rio de Janeiro: Revan, 2002.

O "novo ritmo da redação" de O Globo: a prioridade ao jornalismo digital e seus reflexos nas condições de trabalho e produção da notícia. Parágrafo, v. 2, p. 146-165, 2014.

PAGANOTTI, Ivan. Ecos da censura na regulamentação de meios de comunicação: propostas democráticas de controle e a herança autoritária em Portugal e no Brasil. Eptic, v. 19, n. 1, p. 26-43, 2017.
PEREIRA, Fábio; ADGHIRNI, Zélia. O jornalismo em tempo de mudanças estruturais. Intexto, v. 1, n. 24, p. 38-57, 2011. REBOUÇAS, Edgard. Estratégia retórica dos "donos" da mídia como escudo ao controle social. Líbero, n. 17, p. 41-49, 2006.

\section{REIMBERG, Cristiane. 0 exercício} da atividade jornalística na visão dos profissionais: sofrimento e prazer na perspectiva teórica da psicodinâmica do trabalho. 2015. 376 f. Tese (Doutorado em Comunicação)-Programa Pós-Graduação em Ciências da Comunicação da Universidade de São Paulo, São Paulo, 2015.

SCHWARTZ, Yves. Conceituando o trabalho, o visível e o invisível. Trabalho, Educação e Saúde, v. 9, supl. 1, p. 19-45, 2011.

\section{Informações sobre 0 artigo}

Resultado de projeto de pesquisa, de dissertação, tese: 0 artigo é resultado da tese de doutorado Reestruturações produtivas no mundo do trabalho dos jornalistas: precariedade, tecnologia e manifestações da identidade profissional (2019). Fontes de financiamento: Conselho Nacional de Desenvolvimento Científico e Tecnológico (CNPq).

Considerações éticas: Não se aplica.

Declaração de conflito de interesses: Não se aplica.

Apresentação anterior: Uma versão preliminar deste artigo foi apresentada no $16^{\circ}$ Encontro Nacional de Pesquisadores em Jornalismo.

Agradecimentos/Contribuições adicionais: Agradeço aos membros da Rede de Pesquisa Trabalho e Identidade dos Jornalistas e aos pareceristas da revista E-Compós pelas valiosas contribuições para este artigo. 


\section{Ethical suffering in the world of work of journalists}

\section{Abstract:}

Based on a qualitative analysis of the semi structured interviews conducted with 15 journalists that have worked in State of São Paulo in 2016, this article conceptualizes a recurrent phenomenon in the trajectories of Brazilian journalists and scarcely documented by the literature, namely, the ethical suffering. Problematizing two explicative keys offered by the sociology of journalism that would take account of infraction of ethical codes as symptoms of class unconscious between the journalists or as an outcome of the transformations of media organizations, this study recovers the framework of political economy of communication to demonstrate the historical persistence of ethical suffering.

\section{Keywords:}

Journalism. Ethics. Work. Suffering. Interview.

\section{El sufrimiento ético en el mundo del trabajo de los periodistas}

\section{Resumen:}

Basado en un análisis cualitativo de entrevistas semi estructuradas realizadas con 15 periodistas que actuaban en el Estado de São Paulo en 2016, este artículo conceptualiza un fenómeno recurrente en las trayectorias de los periodistas brasileños y escasamente documentado por la literatura, a saber, el sufrimiento ético. Problematizando dos claves explicativas ofrecidas por la sociología del periodismo que toman relatos de infracción de los códigos deontológicos como síntoma de inconsciencia de clase entre los comunicadores o como resultado de las transformaciones en las organizaciones de medios, este estudio recupera el marco de la economía política de la comunicación para demonstrar la persistencia del sufrimiento ético.

Palavras clave:

Periodismo. Ética. Trabajo. Sufrimiento. Entrevista.

\section{Thales Vilela Lelo}

Doutor pelo Programa de Pós-Graduação em Ciências Sociais da Universidade Estadual de Campinas - Unicamp. Pesquisador de Pós-doutorado no Departamento de Comunicações e Artes da Universidade de São Paulo ECA-USP, com bolsa da Fundação de Amparo à Pesquisa do Estado de São Paulo (FAPESP). Mestre em Comunicação Social pela Universidade Federal de Minas Gerais. Universidade de São Paulo, São Paulo, Brasil E-mail: thales.lelo@gmail.com 